Methods In the US, the US FDA requires the disease or condition for which the drug is intended will affect fewer than 200000 people in the United States or, if the drug is a vaccine, diagnostic drug, or preventive drug, the persons to whom the drug will be administered in the United States are fewer than 200000 per year. Alternatively, for a drug intended for diseases or conditions affecting 200000 or more people, or for a vaccine, diagnostic drug, or preventive drug to be administered to 200000 or more persons per year in the United States, there is no reasonable expectation that costs of research and development of the drug for the indication can be recovered by sales of the drug in the United States. In the US, if a sponsor requests orphan-drug designation for a drug for only a subset of persons with a particular disease or condition that otherwise affects 200000 or more people ('orphan subset'), a demonstration that, due to one or more properties of the drug, the remaining persons with such disease or condition would not be appropriate candidates for use of the drug.

In Europe, the EMA expects that the disease is either lifethreatening or debilitating, the medical plausibility of the proposed orphan indication; and importantly, that the prevalence of the condition in the European Union is not more than five in 10,000; or that it is unlikely that marketing the medicinal product in the European Union, without incentives, would generate sufficient return to justify the necessary investment; and furthermore, that no satisfactory method of diagnosis prevention or treatment exists, or if such a method exists, that the medicinal product will be of significant benefit to those affected by the condition.

An example of a prevalence analysis in SLE is shown in table 1.

\begin{tabular}{|c|c|c|}
\hline Parameter & Estimate & Source \\
\hline U.S. Population Estimate & $320,000,000$ & $\begin{array}{l}\text { U.S. Census Bureau (2014), July } 2014 \\
\text { estimate }\end{array}$ \\
\hline Overall U.S. Prevalence of SLE & $\begin{array}{l}97 \text { per } \\
100000 \\
(n=310,400)\end{array}$ & $\begin{array}{l}\text { Upper confidence limit of most } \\
\text { conservative SLE prevalence estimate } \\
\text { from Lim et al. (2014) }\end{array}$ \\
\hline $\begin{array}{l}\text { Proportion of SLE patients with } \\
\text { LN }\end{array}$ & $\begin{array}{l}50 \% \\
(n=155,200)\end{array}$ & Dooley 2007 and Mok et al. 2013 \\
\hline $\begin{array}{l}\text { Proportion of LN patients with } \\
\text { Class III-Class VI LN }\end{array}$ & $\begin{array}{l}92 \% \\
(n=142,784)\end{array}$ & Mok et al., 2013 \\
\hline $\begin{array}{l}\text { Orphan population of SLE } \\
\text { among patients with no Class } \\
\text { III-Class VI LN }\end{array}$ & $n=167616$ & - \\
\hline
\end{tabular}

\section{CT-06 MISSING OUTCOMES IN SLE CLINICAL TRIALS: IMPACT ON ESTIMATING TREATMENT EFFECTS}

${ }^{1}$ Mimi Kim*, ${ }^{2}$ Joan T Merrill, ${ }^{3}$ Kenneth C Kalunian, ${ }^{4}$ Leslie Hanrahan, ${ }^{5}$ Peter M Izmirly. ${ }^{1}$ Albert Einstein College of Medicine; ${ }^{2}$ Oklahoma Medical Research Foundation; ${ }^{3}$ University of California at San Diego; ${ }^{4}$ Lupus Foundation of America; ${ }^{5}$ New York University School of Medicine, USA

\subsection{6/lupus-2018-Ism.78}

Background Missing data due to drop-out and loss to followup is a common problem in SLE trials. The usual approaches for handling this issue include analyzing only subjects with complete data (complete case analysis; CC), last observation carried forward (LOCF), or imputing non-responses for missing outcomes (non-responder imputation; NRI). However, the validity of these methods depends on strong assumptions about the missing data mechanism. Multiple imputation (MI) is a flexible model-based technique that accounts for uncertainty in the imputation process by generating several possible values for the missing data, resulting in multiple complete data sets. These are analyzed separately and results are combined. MI is being used more widely in different disease settings but has not been applied to analyze the primary outcome in a SLE trial. We explored the use of MI to address missing data in the composite outcome, SLE Responder Index (SRI) -5 , using data from patients assigned to standard of care (SoC) in a 52 week trial.

Methods Data on 279 SLE patients randomized to SoC for 52 weeks who were receiving mycophenolate mofetil (MMF), azathioprine, or methotrexate at entry were obtained from the Lupus Foundation of America-Collective Data Analysis Initiative database. Multiple imputation using chained equations was applied to handle missing data in an analysis to evaluate differences in SRI-5 response rates at 52 weeks between patients on MMF and the other immunosuppressants (nonMMF). Three different imputation models were considered that included various combinations of longitudinal measures of disease activity (both composite and individual measures) and patient characteristics. Results were compared to estimates using the CC, LOCF, and NRI.

Results Missing data rates were $32 \%$ in the MMF and 23\% in the non-MMF groups. As expected, the NRI missing data approach yielded the lowest response rates; the smallest and least significant estimates of between group differences were observed with LOCF (table 1). Group differences were magnified with all three MI models compared to results of other methods. Imputing SRI-5 directly (MI-1) versus the individual components (MI-2) yielded nearly identical results.

Conclusions Given the limitations of conventional approaches for handling missing data, the MI method should also be considered in SLE trials. However, results can vary depending on the imputation model that is used, and the assumptions required for validity of this and other missing data methods must be justified. Sensitivity analysis using different approaches is important to demonstrate robustness of results especially when missing data rates are non-negligible.

\begin{tabular}{|c|c|c|c|c|c|}
\hline $\begin{array}{l}\text { Missing data } \\
\text { approach }\end{array}$ & $\begin{array}{l}\text { Non- } \\
\text { MMF }\end{array}$ & MMF & Difference & $95 \% \mathrm{Cl}$ & P-value \\
\hline CC & $46.8 \%$ & $29.3 \%$ & $17.5 \%$ & $1.7 \%$ to $33.3 \%$ & 0.043 \\
\hline LOCF & $40.6 \%$ & $30.0 \%$ & $10.6 \%$ & $-2.7 \%$ to $23.9 \%$ & 0.13 \\
\hline NRI & $36.1 \%$ & $20.0 \%$ & $16.1 \%$ & $4.1 \%$ to $28.0 \%$ & 0.019 \\
\hline $\mathrm{MI}^{*}{ }^{*}$ & $47.6 \%$ & $28.5 \%$ & $19.1 \%$ & $4.6 \%$ to $33.5 \%$ & 0.010 \\
\hline MI-2* & $46.0 \%$ & $27.0 \%$ & $19.0 \%$ & $4.3 \%$ to $33.6 \%$ & 0.011 \\
\hline $\mathrm{MI}^{-3^{*}}$ & $47.6 \%$ & $29.7 \%$ & $17.9 \%$ & $3.1 \%$ to $32.7 \%$ & 0.018 \\
\hline
\end{tabular}

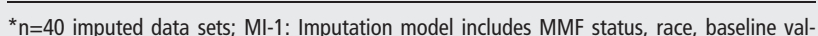
ues of SLEDAI, PGA, BILAG score, protein/creatinine ratio, anti-dsDNA, SRI-5 at 12, 24, 36, 44, 52 weeks; MI-2: Imputation model same as MI-1 but separately imputing components of SRI-5 (SLEDAI, BILAG, PGA);MI-3: Imputation model includes MMF, SRI-5 at all time points.

Acknowledgements Lupus Foundation of America Collective Data Analysis Initiative Group. 